\title{
A unifying process capability metric
}

\author{
John Jay Flaig \\ Applied Technology (USA) \\ johnflaig@yahoo.com
}

Received December 2008

Accepted April 2009

\begin{abstract}
A new economic approach to process capability assessment is presented, which differs from the commonly used engineering metrics. The proposed metric consists of two economic capability measures - the expected profit and the variation in profit of the process. This dual economic metric offers a number of significant advantages over other engineering or economic metrics used in process capability analysis. First, it is easy to understand and communicate. Second, it is based on a measure of total system performance. Third, it unifies the fraction nonconforming approach and the expected loss approach. Fourth, it reflects the underlying interest of management in knowing the expected financial performance of a process and its potential variation.
\end{abstract}

Keywords: process capability, profitability, variation in profit

\section{Introduction}

The proposed process capability metric is designed to be a management tool that can use to help guide processes towards greater and more stable economic performance. It provides a more complete view of process performance than other capability assessment approaches, which typically focus on components of the system rather than an end-to-end measure of total system performance. In fact, this metric is the only capability metric that assesses both the expected performance and the variation of the most fundamental economic measure of 
process capability - profitability. Thus, the new metric should significantly help improve the bottom line financial results of companies that choose to adopt it.

In the recent survey article on Process Capability Indices, by Kotz and Johnson, several discussants suggested that a single metric is insufficient to adequately describe process capability and that multiple metrics are required (Kotz, 2002) (Bothe, 2002). Further, Hubele (2002) and Ramberg (2002) suggest that whatever capability metrics are proposed they should express both the expected value of the metric and an estimate of its variation. The author agrees with both of these suggestions, so the ordered pair notation, $C_{M}=[E(M), S D(M)]$ will be used, where $M$ denotes the metric, $C_{M}$ denotes the $M$-capability metric, $E(M)$ is the expected value of the metric, and $\mathrm{SD}(\mathrm{M})$ is the standard deviation of the metric. For additional background on process capability measurement the reader is referred to the text by Pearn and Kotz (Pearn, 2006), or the book by Bothe (Bothe, 2001).

As most practitioners are aware statisticians view all of the commonly used capability indices (i.e., Cp, Cpk, Cpm, and fraction nonconforming (NC)) with various degrees of concern. Hence, numerous "better" alternatives have been proposed (more than 100 at last count). There has been great deal of research in the area of engineering process capability metrics but very little on economic metrics and almost none on dual economic metrics for assessing process capability. One of the more recent economic proposals is to use the quadratic expected loss as a capability metric. However, there are concerns with this metric also which will be discussed next.

\section{The loss metric}

Some authors (Spiring, 2002; Ramberg, 2002) have proposed using the economic expected loss metric (EL) as a capability measure. This metric has the advantage that it reflects the more modern and reasonable quality loss philosophy rather than the classic binary cost model (used in the fraction nonconforming metric NC). Thus, the expected loss might be a good choice for a metric, if it mapped seamlessly into the underlying concept of capability.

However, though EL probably does reflect a part of the general concept of process "goodness", if used alone, it does not delineate between internal and external losses or provide a measure of profitability, which are key concerns of 
management. Thus, from a management and communication point of view, it is not a sufficient statistic from which to infer the capability of the process. The source of the problem, in the author's opinion, is that the expected loss metric focuses only on costs and this is not a sufficient basis for a metric that is supposed to span the space of interests of all concerned in assessing process capability. To understand why a cost based model of capability does not provide sufficient information it is necessary to consider the entire production process as a system. This is the focus of the next section.

\section{The cost fallacy}

One of the classic concerns of process improvement is how to minimize cost, the assumption being that this will lead to increased profitability. Intuitively this seems like a reasonable assumption, but is it a valid assumption? The answer unfortunately is no. As Liebhold (2001) points out:

One major point has been overlooked in most quality engineering publications: the overriding goal of companies within an industry is the maximization of profit to allow for reinvestment and further growth and profits. Indeed, whereas most research focuses on quality improvement and its related cost, it does not take into account the impact of quality on quantities sold and the sale price. Because the survival and development of a company depends on profit generation, reduction in costs is useless if it is not compared to its direct impact on revenues.

Thus, a higher-level metric is needed, one that captures both the cost and revenue performance of the process (i.e., a total business system performance metric). The logic embodied in this argument lead us to propose the more complete process performance measure -- profitability in a previous paper (Flaig, 1999). Using profit as a system metric is not a new concept as several authors (e.g., Leland, 1978; Lau, 1988; Liebhold, 2001) have suggested it. However, it has never really been adopted as a standard management metric for assessing process capability. For example, the survey article by Kotz and the book by Bothe do not cite a single profit based capability metric. In addition, none of the previously proposed economic metrics included the variation in profit as an important production system attribute. Thus, clearly missing an issue that is of great concern to management. 


\section{The profit metric}

This approach to process capability assessment can be applied to any enterprise that produces a product for a profit. The business model below assumes that all units are inspected before shipping, and inspection is $100 \%$ effective (i.e., there is no measurement system error), and that all units produced during the period are sold (i.e., no inventory accumulation). It is assumed that this analysis is for a stable process and at a fixed point on the products supply and demand curve.

The business performance metric used in this paper is defined to be:

$$
\text { Gross Profit }=\text { Net Sales Revenue }- \text { Cost of Goods Sold }
$$

On a "per unit" basis equation 1 becomes:

Gross Profit per Unit (GPPU) $=[$ RPU $\times($ Process Yield $)]-[$ COGS per Unit $]$

where RPU is the revenue per unit (assumed constant under the assumptions given above).

COGS is the Cost of Goods Sold and is given by:

COGS $=$ [Beginning Inventory + Cost of Product Produced - Ending Inventory $]$ Assuming that beginning and ending inventories are equal, then equation 2 becomes:

$$
\text { GPPU }=[\text { RPU (Process Yield) }]-[\text { Cost of Product Produced per Unit }]
$$

Let $x$ be the measurement of a Quality characteristic of interest on a unit. A unit is defined as nonconforming (NC) if $x>$ Upper Spec Limit (USL) or $x<$ Lower Spec Limit (LSL). If NC is the process fraction nonconforming, then $1-\mathrm{NC}$ is the process yield. Further, the cost of product per unit, CPPU, is given by:

$$
\mathrm{CPPU}=\mathrm{C}_{\mathrm{L}}+\mathrm{C}_{\mathrm{M}}+\mathrm{C}_{\mathrm{E}}+\mathrm{C}_{\mathrm{F}}+\mathrm{C}_{\mathrm{O}}
$$

where $C_{L}$ is the cost of labor, $C_{M}$ is the cost of materials, $C_{E}$ is the cost of equipment, $C_{F}$ is the cost of product failure, and $C_{O}$ is all other production costs. In addition it should be noted that NC is a function of mean and standard deviation of the quality characteristic and its specification limits. 
The gross profit per unit is then given by:

$$
\mathrm{GPPU}=[\mathrm{RPU}(1-\mathrm{NC})]-\left[\mathrm{C}_{\mathrm{L}}+\mathrm{C}_{\mathrm{M}}+\mathrm{C}_{\mathrm{E}}+\mathrm{C}_{\mathrm{F}}+\mathrm{C}_{\mathrm{O}}\right]
$$

If operating costs (i.e., sales and marketing, and general and administrative) were included, then equation 5 would reflect net profit rather than gross profit.

There are three approaches to estimation of the product failure cost $\mathrm{C}_{\mathrm{F}}$. They are quality cost, process cost, and quality loss (Campanella, 1999). The quality loss approach characterized by the Taguchi quadratic expected loss per unit function (EL) will be used in this paper to estimate $C_{F}$.

Replacing $C_{F}$ in equation 5 with EL yields:

$$
\mathrm{GPPU}=[\mathrm{RPU}(1-\mathrm{NC})]-\left[\mathrm{C}_{\mathrm{L}}+\mathrm{C}_{\mathrm{M}}+\mathrm{C}_{\mathrm{E}}+\mathrm{C}_{\mathrm{O}}+\mathrm{EL}\right]
$$

The proposed dual economic process capability metric for gross profit is defined to be:

$$
C_{G P}=[E(G P P U), S D(G P P U)], \text { or more simply }[E(G P), S D(G P)]
$$

Assuming our company produces a product that has a stable quality characteristic distribution (not necessarily Normal) having mean $\mu$, standard deviation $\sigma$, with a fixed process target $T$ and constant specification limits (LSL, USL), then the quadratic expected loss is given by $\mathrm{EL}=\mathrm{c}\left(\sigma^{2}+(\mu-\mathrm{T})^{2}\right)$, where $\mathrm{c}$ is the constant estimated economic loss per unit, and $T$ is the process target. So the first term, $E(G P)$, in the $C_{G P}$ metric is given by:

$$
E(G P)=[R P U(1-E(N C))]-\left[C_{L}+C_{M}+C_{E}+C_{O}+C E\left(s^{2}+(m-T)^{2}\right)\right]
$$

where $m$ is the arithmetic mean, and $s$ is the Root Mean Square (RMS) standard deviation. Thus NC and EL are functions of the random variables $m$ and $s$, which are estimates of the population parameters $\mu$ and $\sigma$ respectively. The functional form of NC is not specified but can be approximated by modeling the process distribution (Farnum, 1996; Flaig, 2002) or empirically by periodic sampling of the process.

The second term in our dual $\mathrm{C}_{\mathrm{GP}}$ metric, $\mathrm{SD}(\mathrm{GP})$, must still be determined. So taking the variance of equation 6 yields: 


$$
V(G P)=V\left([R P U(1-N C)]-\left[C_{L}+C_{M}+C_{E}+C_{O}+E L\right]\right)
$$

Since RPU, $C_{L}, C_{M}, C_{E}$, and $C_{O}$ are constants, and NC and $E L$ are functions of $m$ and $\mathrm{s}$, then distributing the variance operator over equation 9 yields:

$$
\begin{aligned}
V(G P) & =V(-R P U N C))+V(-E L)+2(-R P U)(-1) \operatorname{Cov}(N C, E L) \\
& =R P U^{2} V(N C)+V(E L)+2 R P U \operatorname{Cov}(N C, E L)
\end{aligned}
$$

where $\operatorname{Cov}(N C, E L)=\rho(N C, E L) S D(N C) S D(E L)$

If sufficient daily or weekly production data are available from a stable process, then all the terms in E(GP) and V(GP) can be estimated by periodic sampling of the process data. That is, the practitioner could estimate the correlation coefficient $\rho(N C, E L)$ and other terms with a known degree of confidence and hence provide an estimate of $\mathrm{C}_{\mathrm{GP}}$. However, the terms in equation 10 may be further simplified for computation purposes by finding $\mathrm{V}(\mathrm{EL})$ and $\mathrm{V}(\mathrm{NC})$.

Since $\mathrm{c}$ is a constant, and $\mathrm{m}$ and $\mathrm{s}$ are random variables, it follows that $\mathrm{EL}$ is $\mathrm{a}$ random variable. So taking the variance of the expected loss function yields:

$$
\begin{aligned}
V(E L) & =V\left(c\left(s^{2}+(m-T)^{2}\right)\right) \\
& =c^{2}\left[V\left(s^{2}+(m-T)^{2}\right)\right] \\
& =c^{2}\left[V\left(s^{2}\right)+V\left((m-T)^{2}\right)+2 \operatorname{Cov}\left(s^{2},(m-T)^{2}\right)\right]
\end{aligned}
$$

Further, since $\mathrm{s}$ is the RMS standard deviation, then equation 12 can be expanded as follows:

$$
\mathrm{V}\left(\mathrm{s}^{2}\right)=\mathrm{E}\left(\mathrm{s}^{4}\right)-\mathrm{E}^{2}\left(\mathrm{~s}^{2}\right)=\frac{\mu_{4}-\mu_{2}^{2}}{\mathrm{n}} \text {, where } \mu_{r}=1 / \mathrm{n} \sum_{i=1}^{n}(\mathrm{x}-\mathrm{m})^{r}
$$

and

$$
\mathrm{V}\left((\mathrm{m}-\mathrm{T})^{2}\right)=\mathrm{E}\left((\mathrm{m}-\mathrm{T})^{4}\right)-\mathrm{E}^{2}\left((\mathrm{~m}-\mathrm{T})^{2}\right)=\mu_{1}^{\prime 4}-\mu_{1}^{\prime 4}=0 \text {, where } \mu_{r}^{\prime}=1 / \mathrm{n} \sum_{i=1}^{n}(\mathrm{X}-\mathrm{T})^{r}
$$

and 


$$
\begin{aligned}
\operatorname{Cov}\left(s^{2},(m-T)^{2}\right) & =\rho\left(s^{2},(m-T)^{2}\right) \operatorname{SD}\left(s^{2}\right) \operatorname{SD}\left((m-T)^{2}\right) \\
& =\rho\left(s^{2},(m-T)^{2}\right) \sqrt{\frac{\mu_{4}-\mu_{2}^{2}}{n}} 0=0
\end{aligned}
$$

Thus,

$$
\mathrm{V}(\mathrm{EL})=\mathrm{c}^{2}\left(\frac{\mu_{4}-\mu_{2}^{2}}{\mathrm{n}}+0+2 \rho\left(\mathrm{s}^{2},(\mathrm{~m}-\mathrm{T})^{2}\right) \sqrt{\frac{\mu_{4}-\mu_{2}^{2}}{\mathrm{n}}} 0\right)=\mathrm{c}^{2}\left(\frac{\mu_{4}-\mu_{2}^{2}}{\mathrm{n}}\right)
$$

All that remains to be done is to determine the standard deviation of the fraction nonconformance, $\mathrm{SD}(\mathrm{NC})$. The variance of $\mathrm{NC}$ is given by:

$$
\begin{aligned}
& V(N C)=N C(1-N C) / n \text {, from which it follows that, } \\
& S D(N C)=[(N C(1-N C)) / n]^{1 / 2}
\end{aligned}
$$

Thus, the standard deviation of gross profit, GP, is given by:

$$
S D(G P)=\left[R P U^{2} V(N C)+V(E L)+2 R P U \rho(N C, E L) S D(N C) S D(E L)\right]^{1 / 2}
$$

Combining the two performance measures $E(G P)$ and $S D(G P)$ to form the gross profit capability metric $\mathrm{C}_{\mathrm{GP}}=[\mathrm{E}(\mathrm{GP}), \mathrm{SD}(\mathrm{GP})]$ gives the practitioner a measure of process capability that is directly connected to a concrete measure of financial performance and one that management is keenly interested in knowing.

\section{A real world example}

The dual response process capability optimization technique was discussed in a previous paper (Flaig, 2002) and the same technique will be used in this example. However, in this case the goal is to optimize $C_{G P}$ in the sense of maximizing the expected profit, E(GP), and simultaneously minimizing the variation in profit, $\mathrm{SD}(\mathrm{GP})$, to achieve the most economically capable process. However, since these dual objectives sometimes conflict the practitioner must decide on an optimization approach. There are several approaches to dual response optimization (Copeland, 1996; Del Castillo, 1993), but the profit signal-to-noise ratio (i.e., SN(GP) = $\mathrm{E}(\mathrm{GP}) / \mathrm{SD}(\mathrm{GP}))$ will be used in this paper.

In order to determine and optimize the $\mathrm{C}_{\mathrm{GP}}$ metric two items are required: 
- An economic model of the process (i.e., a business model).

- A process model (i.e., an adequate model of a stable process)

Now, consider the following real world example of a pipe grinding operation (Trietsch, 1997). As noted the inputs are required for the analysis are a business model and a process model. Below is a business model for the pipe grinding operation (values not given by Trietsch are provided by the author and are based on typical values observed in industry).

\begin{tabular}{|c|c|c|}
\hline Factor & I nputs & Description \\
\hline \multicolumn{3}{|l|}{ Revenue } \\
\hline Demand Model Type $=$ & 0 & Select a variable or constant demand model (Constant $=0 ;$ Variable $=1$ ) \\
\hline Input Qty $=$ & 100 & Enter the initial quantity of production planned per unit of time (i.e. day, week, etc) \\
\hline Initial RPU $=$ & $\$ 10.00$ & \\
\hline Resulting & $\$ 10.00$ & The expected price that the units should sell for in the market \\
\hline \multicolumn{3}{|l|}{ Costs } \\
\hline \multicolumn{3}{|l|}{ Internal Failure Cost } \\
\hline $\mathrm{NC}$ on the Leith $(\mathrm{NCL})=$ & $0.9 \%$ & The NCL comes from the Johnson model so be sure to check model adequacy \\
\hline $\mathrm{NC}$ on the right $(\mathrm{NCR})=$ & $0.4 \%$ & The NCR comes from the Johnson model so be sure to check model adequacy \\
\hline NC total (NC) & $1.3 \%$ & $\mathrm{NC}=\mathrm{NCL}+\mathrm{NCR}$ \\
\hline First time yield (FTY) & $98.7 \%$ & The first time yield (FTY) is $1-\mathrm{NC}$ \\
\hline Failure cost on Left $(\mathrm{CiL})=$ & $\$ 2.60$ & Enter the average scrap-rework cost (CiL) in \$ per unit for the left side of the distribution \\
\hline Failure cost on Right $(\mathrm{CiR})=$ & $\$ 0.30$ & Enter the average scrap-rework cost ( $\mathrm{CiR}$ ) in $\$$ per unit for the right side of the distribution \\
\hline \multirow[t]{2}{*}{ Expected Loss (Eli) } & $\$ 0.03$ & The empirical expected internal failure cost is $C i L^{*} N C L+C i R * N C R$ \\
\hline & $\$ 0.16$ & The expected loss function estimate of Eli \\
\hline \multicolumn{3}{|l|}{ External Failure Cost } \\
\hline Field failure cost $(\mathrm{Ce})=$ & $\$ 25.00$ & Enter the average field failure cost in \$ per unit \\
\hline Field failure rate $(\mathrm{Pe})=$ & $1 \%$ & Enter the estimated field failure rate $(\mathrm{Pe})$, if it is known. If it is unknown, enter NA \\
\hline Spec Safety Margin \% $=$ & $0 \%$ & Enter the specification safety margin percentage \\
\hline Upper Failure Point (UFP) $=$ & 301.00 & Upper point at which product is sure to fail in the field \\
\hline Lower Failure Point (LFP) $=$ & 299.00 & Lower point at which product is sure to fail in the field \\
\hline Loss factor $(\mathrm{c})=$ & $\$ 12.50$ & Loss function proportionality factor $(c)$ in the equation $L(x)=c(x-T)^{\wedge} 2$ \\
\hline \multirow[t]{2}{*}{ Expected Loss (Ele) $=$} & $\$ 0.25$ & The empirical estimate of ELe based on cost times failure rate, $\mathrm{Ce} * \mathrm{Pe}$ \\
\hline & $\$ 1.81$ & $\begin{array}{l}\text { The expected external failure cost based on the truncated distribution and } \mathrm{ELe}=\mathrm{c}\left(\mathrm{s}^{\wedge} 2+(\mathrm{m} \text { - }\right. \\
\left.\mathrm{T})^{\wedge} 2\right)\end{array}$ \\
\hline \multicolumn{3}{|r|}{ 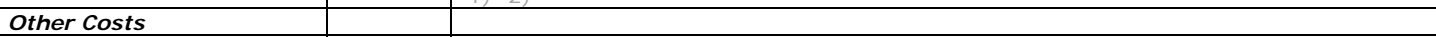 } \\
\hline Materials cost $(\mathrm{Cm})=$ & $\$ 1.80$ & Enter material cost $(\mathrm{Cm})$ in \$ per unit \\
\hline $\begin{array}{l}\mathrm{Cm}(\text { Fixed }=0 ; \text { Variable }=1) \\
=\end{array}$ & 0 & Enter the type of material cost model that applies to your situation \\
\hline Labor Cost $(\mathrm{Cl})=$ & $\$ 0.20$ & Enter labor cost $(\mathrm{Cl})$ in $\$$ per unit \\
\hline Equipment cost $(\mathrm{Ct})$ & $\$ 0.10$ & Enter equipment cost $(\mathrm{Ct})$ in $\$$ per unit \\
\hline All other costs $(\mathrm{Co})=$ & $\$ 0.40$ & Enter all other production costs Co (e.g. prevention, appraisal, facilities) \\
\hline $\begin{array}{l}\text { Analysis approach (Loss = } \\
0, \text { Cost }=1)=\end{array}$ & 0 & Select the financial approach that you want to use inn the analysis and optimization \\
\hline \multicolumn{3}{|r|}{ Quality Loss Approach } \\
\hline Expected Profit $=$ & $\$ 7.19$ & $\mathrm{E}(\mathrm{P})=[\mathrm{RPU}(1-\mathrm{NC})]-[\mathrm{CM}+\mathrm{CL}+\mathrm{CT}+\mathrm{CO}+\mathrm{EL}]$ \\
\hline Std dev of Profit $=$ & $\$ 0.17$ & $\mathrm{SD}(\mathrm{P})=\mathrm{SQRT}[\mathrm{RPU} \wedge 2 \mathrm{~V}(\mathrm{NC})+\mathrm{V}(\mathrm{EL})+2 \mathrm{RPU} r(\mathrm{NC}, \mathrm{EL}) \mathrm{SD}(\mathrm{NC}) \mathrm{SD}(\mathrm{EL})]$ \\
\hline
\end{tabular}

Table 1. "Pipe Grinding Business Model".

It should be noted that for the $\mathrm{C}_{\mathrm{GP}}$ maximization approach to yield reasonable results the practitioner must exercise care in the estimation of the field failure cost, especially intangible costs such as customer dissatisfaction (Campanella, 1999). In addition to the business model a process model is required for our analysis. Trietsch indicates that the pipe grinding process distribution was approximately Normal with $\mu=300, \sigma=0.4$, USL $=301, \mathrm{~T}=300, \mathrm{LSL}=299$, and let us assume that $\rho(N C, E L)=0.2$. The input variables for Generalized Reduced Gradient 
optimization model are $\mathrm{dx}$ and $\mathrm{k}$, where $\mathrm{dx}$ is process mean shift and $\mathrm{k}$ is the process sigma multiplier, and the output variable is the profit signal to noise ratio $\mathrm{SN}(\mathrm{GP})$. From this information it is possible to evaluate the expected performance of the process in its initial state.

\begin{tabular}{|c|c|c|c|}
\hline Objectives & Description & Weights (Wi) & Results \\
\hline DT $\rightarrow 0$ & Minimize the deviation from target & 1 & -0.02 \\
\hline Expected (Profit) $\rightarrow$ Infinity & Maximize profit & 1 & $\$ 7.19$ \\
\hline Std Dev (Profit) $\rightarrow 0$ & Minimize profit variation & 1 & $\$ 0.09$ \\
\hline
\end{tabular}

Table 2. "Expected performance of the process in its initial state".

Since the original observed data was not available, the performance of the pipe grinding operation was simulated based of the parameters given (i.e., 1,000 values were drawn at random from $\mathrm{N}(300,0.4)$ ) with the following results:

The process in its initial state (i.e., $d x=0, k=1$ ) has capability CGP $=[\$ 7.19$, $\$ 0.09$ ] and $\mathrm{Cpk}=0.82$.

Now suppose experiments were performed that resulted in a $10 \%$ reduction in variation, then adjusting the mean shift $(\mathrm{dx})$ and sigma multiplier $(k)$ inputs to achieve profit signal-to-noise maximization results in the following:

\begin{tabular}{|c|c|c|c|}
\hline Objectives & Description & Weights (Wi) & Results \\
\hline $\mathrm{NC} \rightarrow 0$ & Minimize the fraction nonconforming & 1 & 6,094 \\
\hline $\mathrm{NS} \rightarrow 0$ & Minimize the sensitivity to variation & 1 & 1,768 \\
\hline DT $\rightarrow 0$ & Minimize the deviation from target & 1 & 0.03 \\
\hline $\mathrm{S} \rightarrow 0$ & Minimize the process variation & & 0.3570 \\
\hline Expected (Profit) $\rightarrow$ Infinity & Maximize profit & 1 & $\$ 7.64$ \\
\hline Std Dev (Profit) $\rightarrow 0$ & Minimize profit variation & 1 & $\$ 0.07$ \\
\hline
\end{tabular}

Table 3. "Expected performance of the process with a 10\% reduction in variation".

when the inputs are set to $d x=0.05$, and $k=0.90$. The adjusted process has capability under these conditions of $C_{G P}=[\$ 7.64, \$ 0.07]$ and $C p k=0.91$.

If these operating conditions could be achieved, then the expected fraction nonconforming would be reduced by 7,375 defectives per million (45\%), profits would increase by $\$ 0.45(6 \%)$, and the standard deviation of profits would decrease by $\$ 0.02(22 \%)$. As illustrated in this example, using the $\mathrm{C}_{\mathrm{GP}}$ metric for optimization results in a significant improvement in economic process capability performance. 


\section{Conclusions}

As the example shows the use of the profit metric $C_{G P}=[E(G P), S D(G P)]$ has significant advantages over $\mathrm{Cpk}$ in driving process improvement. Similarly, it can be shown that it also offers advantages over other capability metrics such as $\mathrm{Cp}$, Cpm, Cpmk, NC, or dual metrics such as $C_{N C}=[N C, N S]$, and the expected loss metric $C_{E L}=[E(E L), S D(E L)]$ because:

1. The profit metric $C_{G P}$ focuses on bottom line issues -- profit and profit variation rather than components of production system performance such as costs, the ratio of specification width to process width, or fraction nonconforming rates.

2. The profit metric $C_{G P}$ does not mislead management into adopting operating conditions that may actually sub-optimize profitability as some other capability indices such as Cpk and Cpm can (Flaig, 2002). This fact alone constitutes a major change in the area of process optimization practice as many people now follow the Six Sigma methodology of using Cpk as the process optimization metric.

3. The profit metric $\mathrm{C}_{\mathrm{GP}}$ includes both $\mathrm{NC}$ and $\mathrm{EL}$ as input variables so it offers an approach that unifies these two contending process capability analysis philosophies. Clearly, the nonconformance rate and the expected loss are both important components in any reasonable view of what constitutes process capability. Hence, rather than arguing that one is better than the other the $\mathrm{C}_{\mathrm{GP}}$ metric incorporates the value of both. Thus providing a unification of the concepts and making the controversy mute.

4. The profit metric $C_{G P}$ focuses on two key financial indices by which all processes are judged - expected profit and the stability of profit generation. Thus, it provides an excellent process performance communication tool, and one that has a good chance of being implemented by management.

There are a vast number of process capability metrics to choose from, many of which are complex, non-intuitive, and hard to understand and communicate. Asking people to adopt a new metric requires that it fulfill an unmet need and be superior to other capability metrics in each of the areas listed above to have any chance of implementation. The only metric that seems to meet these requirements and fulfill management's unmet need for a systematic capability measure is the $\mathrm{C}_{\mathrm{GP}}$ metric. 


\section{References}

Bothe, D. R. (2001). Measuring Process Capability. Landmark Publishing, Inc., Cedarburg, WI.

Bothe, D. R. (2002). PCI Discussion. Journal of Quality Technology, 34(1), 32-37.

Campanella, J. et. al. (1999). Principles of Quality Costs. ASQ Quality Press, Milwaukee, WI.

Copeland, K. A. F., \& Nelson, P. R. (1996). Dual Response Optimization via Direct Function Minimization. J ournal of Quality Technology, 28(3), 331-336.

Del Castillo, E., \& Montgomery D. C. (1993). A Nonlinear Programming Solution to the Dual Response Problem. Journal of Quality Technology, Vol. 25, No. 3, pp. 199-204.

Farnum, N. R. (1996). Using Johnson Curves to Describe Non-normal Process Data. Quality

Flaig, J. J. (1999). Process Capability Sensitivity Analysis. Quality Engineering, Marcel Dekker, 11(4), 587-592.

Flaig, J. J. (2002). Process Capability Optimization. Quality Engineering, Marcel Dekker, 15(2), 233-242.

Hubele, N. F. (2002). PCl Discussion. J ournal of Quality Technology, 34(1), 20-22.

Liebhold, V. S., Kimbler, D. L., \& Gramopadhye, A. K. (2001). A Profit-Based Model Allowing for Quality Achievement and Manufacturing Process Selection. Quality Engineering, Marcel Dekker, 14(1), 25-32.

Leland, H. E. (1972). Theory of the Firm Facing Uncertain Demand. American Economic Review, 62(3), 278-291.

Lau, H.-L.A., \& Lau H. S. (1988). The Newsboy Problem with Price Dependent Demand Distribution. IIIE Transactions, 10, 409-415.

Kotz, S., \& Johnson, N. L. (2002). Process Capability Indices - A Review. Journal of Quality Technology, 34(1), 2-19. 
Pearn, W. L., Kotz, S., \& Johnson, N. L. (1992). Distributional and Inferential Properties of Process Capability Indices. Journal of Quality Technology, 24(4), 216-231.

Pearn, W. L., \& Kotz, S. (2006). Encyclopedia and Handbook of Process Capability Indices. World Scientific Publishing Company, Vol. 12.

Ramberg, J. S. (2002). PCI Discussion. Journal of Quality Technology, 34(1), 4550.

Spiring, F., Cheng, S., Yeung, A., \& Leung, B. (2002). PCl Discussion. Journal of Quality Technology, 34(1), 23-27.

Trietsch, D. (1997). The Five/Ten Rule: A Constrained-Loss Economic Process Adjustment Procedure. Quality Engineering, Marcel Dekker, 10(1), 85-95.

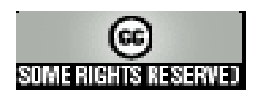

Article's contents are provided on a Attribution-Non Commercial 3.0 Creative commons license. Readers are allowed to copy, distribute and communicate article's contents, provided the author's and Journal of Industrial Engineering and Management's names are included. It must not be used for commercial purposes. To see the complete license contents, please visit http://creativecommons.org/licenses/by-nc/3.0/. 